\title{
Integrando salud bucal en los niños con discapacidad. Proyecto de Extensión
}

Sofía de los Milagros Alí Profesora Adjunta. Cátedra Odontología Social y Comunitaria. Facultad de Odontología. UNNE

Roxana Lilian Blanco Auxiliar Docente. Cátedra Odontología Social y Comunitaria. Facultad de Odontología. UNNE

María Alejandra Meana Auxiliar Docente. Cátedra Odontología Social y Comunitaria. Facultad de Odontología. UNNE

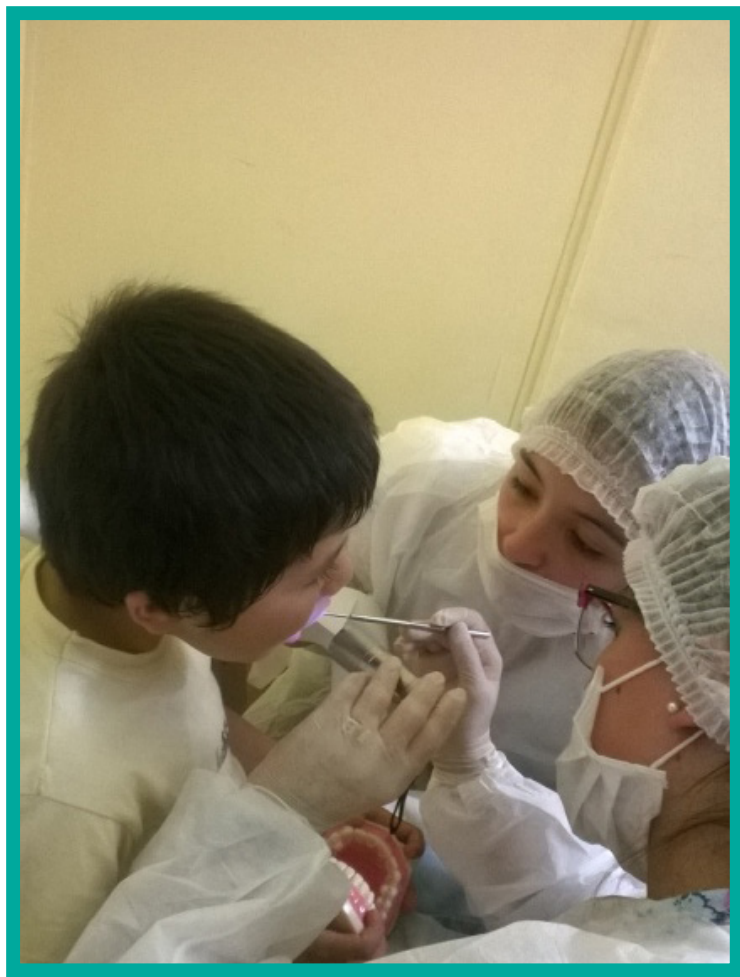

El Proyecto Integrando Salud Bucal en los $\mathrm{Ni}$ ños con Discapacidad, perteneciente al Programa UNNE en el medio y ejecutado por docentes y alumnos de la Cátedra Odontología Social y Comunitaria (Facultad de Odontología) desarrolló sus actividades en el Centro de Atención al Desarrollo de la Infancia y adolescencia.

Los destinatarios fueron 95 niños con discapacidad intelectual de alta vulnerabilidad social, asistentes a dicho Centro, el cual se encuentra ubicado en la Ciudad Capital de Corrientes. Los objetivos de este proyecto fueron:

- Contribuir al mejoramiento de la calidad de vida de 95 chicos con discapacidad intelectual, mediante la implementación de prácticas vinculadas a la promoción, prevención y recuperación de la salud en general y del componente bucal en particular.

- Instruir y fortalecer el rol del personal del centro, padres o tutores.

- Establecer las causas de la mala salud bucal en los niños con discapacidad intelectual.

- Fomentar el registro de información como fuente de datos para el seguimiento y monitoreo de las familias. 
80
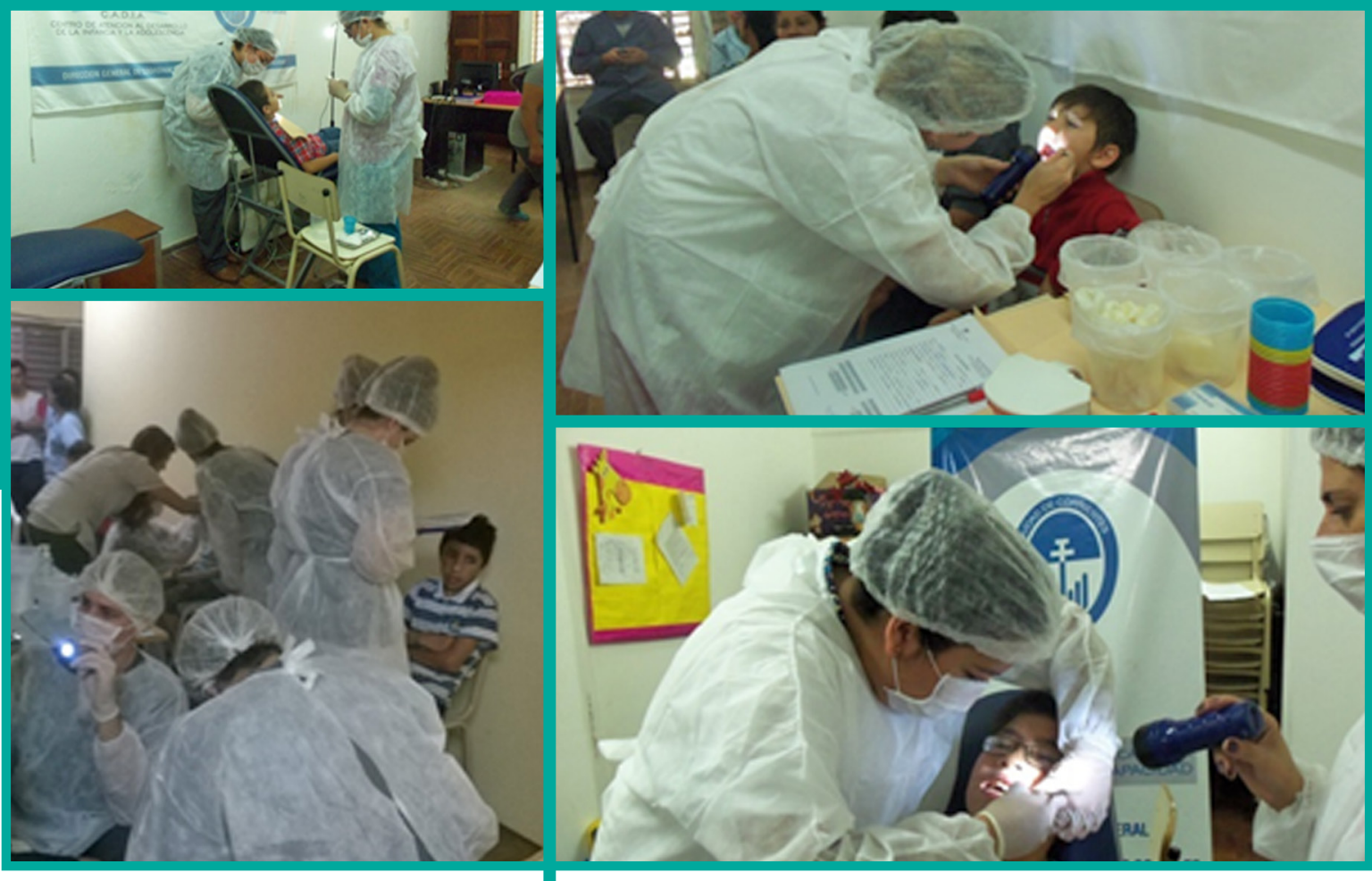

Se desarrollaron actividades en tres etapas

Primera Encuentros de Presentación con los padres, tutores y encargados de la Institución.

Etapa Talleres dirigidos a la motivación y al fortalecimiento de actividades de educación para la salud.

Segunda Continuación con los talleres de capacitación y fortalecimiento.

Etapa Realización de tratamientos odontológicos preventivos y restauradores.

Evaluaciones de Procesos a fin de verificar el cumplimiento de los objetivos.

Gestión en la comunidad para incentivar el apoyo al programa.

Tercera Continuación con los talleres de capacitación y fortalecimiento

Etapa Continuación con los tratamientos preventivos y restauradores.

Presentación y difusión de las actividades a la comunidad.

Difusión en eventos científicos institucionales y nacionales.

Resultados de la actividad

Al término de 12 meses

\begin{tabular}{cl}
\hline 95 & $\begin{array}{l}\text { niños con discapacidad intelectual } \\
\text { documentados }\end{array}$ \\
\hline $60 \%$ & $\begin{array}{l}\text { de las madres ayudaran a sus hijos } \\
\text { en las prácticas de higiene bucal }\end{array}$ \\
\hline $40 \%$ & de altas integrales de salud oral \\
\hline $60 \%$ & de altas básicas \\
\hline $70 \%$ & $\begin{array}{l}\text { de piezas dentarias con tratamiento } \\
\text { restaurador }\end{array}$ \\
\hline
\end{tabular}

La institución realizó actividades de promoción y educación sanitaria a fin de lograr multiplicación de experiencias.

\section{Impacto}

Durante I 2 meses consecutivos, se instaló una sólida infraestructura para la promoción de la salud, donde el personal de dicha institución fue invitado a participar, docentes y alumnos universitarios, desarrollaron prácticas de colaboración multidisciplinarias en apoyo la salud general y bucal de 95 niños con discapacidad intelectual los cuales fueron beneficiarios directos. 